\title{
REDUÇÃO DA MAIORIDADE PENAL: DISCUSSÃO ACERCA DESSA PROPAGADA SOLUÇÃO PARA REDUÇÃO DA CRIMINALIDADE JUVENIL
}

\author{
REDUCTION OF CRIMINAL AGE: \\ DISCUSSION ABOUT THIS PROPAGATED SOLUTION FOR \\ REDUCTION OF JUVENILE CRIME
}

\begin{abstract}
DIEGO MENDES DE SOUSA
Especialista em Politicas Públicas e Gestão Governamental, atuando como Superintendente de de Infraestrutura e Logística da

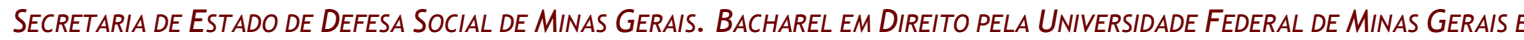
AdMINISTRACÃo Pública PELA Fundaç̃o JoÃo PINHEIRO. dgmsousa@gmail.com
\end{abstract}

LETÍCIA CANCELA DE OLIVEIRA Especialista em Políticas Públicas e Gestão Governamental atuando na Assessoria de Gestão EstratéGICA E Inovação da SeCRETARIA de Estado de Defesa Social de Minas Gerals. Bacharel em Direito pela Universidade Federal de Minas GeraIS e AdministraÇÃo Pública

PELA FundAÇ̃̃o JoÃo PINHEIRO.

leticiacancela@yahoo.com.br

LUIZA HERMETO COUITINHO CAMPOS

Especialista em Políticas Públicas e Gestão Governamental, atuando o Gabinete da Secretária Adjunta da Secretaria de Estado de Defesa Social. Bacharel em Administração Pública pela Fundação João Pinheiro, e cursando especialização em Políticas Públicas pela Universidade Federal de Minas Gerais.

luhermeto@hotmail.com

\section{RESUMO}

0 presente artigo pretende trazer uma análise da questão da maioridade penal, sua evolução histórica, e as diversas posições doutrinárias acerca do assunto tratado. Além disso, traz uma análise do Brasil em relação ao mundo e, mais especificamente, traz dados da incidência infanto juvenil em Belo Horizonte, Minas Gerais, para demonstrar que, de uma forma geral o Brasil não destoa muito das médias da maioridade penal pelo Mundo, e que a taxa de adolescentes envolvidos em atos infracionais são menores se comparadas as médias globais. Portanto, não deve-se pensar na redução da maioridade penal como forma de redução da criminalidade infanto juvenil, e sim formas de inclusão social desses adolescentes, para que eles não voltem a cometer delitos e a efetiva aplicação das diretrizes dadas pelo Estatuto da Criança e Adolescente (ECA), bem como a fiscalização de sua aplicabilidade pelas autoridades públicas.

Palavras-chave: adolescente infrator; delito; maioridade penal.

\begin{abstract}
The article intends to bring an analysis of the issue of age in criminal responsibility, its historical evolution, and the various doctrinal positions on the subject. It also offers an analysis of Brazil in relation to the world and, more specifically, brings incidence criminal data from the Children and Youth in Belo Horizonte, Minas Gerais to demonstrate that, in general Brazil does not variate to much of the ages of criminal responsibility for the world, and that rate of teen involved in offenses are minor compared to global averages. Therefore, one should not think in reducing the age of criminal responsibility as a way of reducing juvenile crime childish, but forms of social inclusion of adolescents, so they return not to commit crimes, and effective implementation of the guidelines given by the Estatuto da Criança e Adlolescente (ECA), and the monitoring of its applicability by public authorities.
\end{abstract}

Keywords: Juvenile criminal; crime; age of criminal responsibility. 


\section{SUMÁRIO}

INTRODUÇAO; 1 TEORIA DO DELITO; 1.1 Conceito de crime; 1.2 A infração; 2 MAIORIDADE PENAL: CONCEITOS, CRITÉRIOS E EVOLUÇÃO HISTÓRICA; 2.1 Maioridade Penal: evolução histórica; 2.1.1 Período Colonial; 2.1.2 Período Imperial; 2.1.3 Período Republicano; 2.1.4 Período Pós $2^{\mathrm{a}}$ Guerra; 3 POSIÇÕES DOUTRINÁRIAS; 3.1 Favoráveis à redução da maioridade penal; 3.2 Contrária à redução da maioridade penal; 4 MAIORIDADE PENAL PELO MUNDO; 5 INCIDÊNCIA INFRACIONAL INFANTO JUVENIL EM BELO HORIZONTE; CONCLUSÃO; REFERÊNCIAS.

\section{INTRODUÇÃO}

A cada momento que se tem notícia de crianças e adolescentes envolvidos em atos criminosos, iniciam-se inúmeros debates entre favoráveis e contrários à redução da maioridade penal. Os primeiros acreditando, entre outras coisas, que a redução da maioridade penal contribuiria para desencorajar crianças e adolescentes a praticar condutas delituosas ou, caso isso não seja possível, fazer com que "realmente" sejam punidos, pois, acreditam que o Estatuto da Criança e do Adolescente (ECA) não é um diploma legal adequado à punição dos infratores. Utilizam também como argumento a ideia de que os adolescentes já possuem completo discernimento para efetuarem o juízo valorativo da conduta que realizam, em outras palavras, sabem o que é certo e que é errado. Já o segundo grupo não entende que a solução seria reduzir a maioridade penal, mas, sim, a efetiva aplicação do ECA. Para esses, o fato é que o ECA nunca fora materialmente aplicado e que a única consequência possível com a redução da maioridade penal seria superlotar ainda mais o sistema prisional nacional. Ainda trabalham a ideia de adolescentes enquanto pessoas em situação peculiar de desenvolvimento, conforme trata o Estatuto, uma vez que ainda não estão completamente formados do ponto de vista físico e mental.

Dentro desse emaranhado de ideias se encontra a discussão em relação à redução ou não da imputabilidade penal a crianças e adolescente. E, como dito, a aparição de crianças e adolescentes envolvidos em crimes serve como combustível para que essa discussão ganhe novos contornos.

Diante dessas discussões, cabe questionar se a redução da maioridade seria uma solução ou mesmo uma medida efetiva na tentativa de se reduzir a criminalidade no Brasil. Se seria um "remédio" eficaz para reduzir a participação de adolescentes no cometimento de atos infracionais ou apenas levaria a uma lotação ainda maior do sistema prisional brasileiro. Se a 
legislação brasileira está distante do que vem sendo praticado no mundo em termos de imputabilidade penal de crianças e adolescente.

Este artigo não tem a pretensão de esgotar a discussão que envolve a redução ou não da imputabilidade penal de crianças e adolescentes no Brasil, apenas tentará analisar posições doutrinárias, trazer alguns elementos que possam enriquecer ainda mais a discussão, inclusive situar o Brasil em relação ao que é praticado mundo afora.

Para tanto, este artigo se estruturará, além desta introdução, em cinco tópicos. 0 primeiro abordará a Teoria Geral do Delito, a evolução do entendimento de delito e/ou crime, com suas antigas e recentes concepções, classificações, abordagem no direito brasileiro. Este estudo é importante para que se possa "polir" e/ou clarear, conceitualmente, a prática de ato infracional frente ao ECA. O segundo tópico será dedicado ao estudo conceitual da maioridade penal: critérios de fixação, sua evolução histórica, conceitos, a imputabilidade de crianças e adolescentes na Constituição Federal de 1988 e no Estatuto da Criança e do Adolescente. 0 terceiro apresentará as posições doutrinárias sobre a redução ou não da maioridade penal. 0 quarto tópico, por sua vez, analisará a questão comparando o Brasil ao restante do mundo e, por fim, expõe alguns dados relativos ao sistema socioeducativo de Minas Gerais, promovendo uma comparação da imputabilidade penal crianças e adolescentes em relação aos diversos crimes.

\section{TEORIA DO DELITO}

Historicamente, a teoria do delito pode ser dividida em três fases de desenvolvimento: o conceito clássico de delito, o conceito neoclássico de delito e conceito finalista de delito.

Von Liszt e Beling construíram o conceito clássico de delito, sendo representado por um movimento corporal, produzindo uma modificação no mundo exterior, vinculando, como se percebe, a conduta ao resultado através do nexo de causalidade. Segundo Bittencourt ${ }^{1}$, “essa estrutura clássica do delito mantinha em partes absolutamente distintas o aspecto objetivo, representado pela tipicidade e antijuricidade, e o aspecto subjetivo, representado pela culpabilidade". Segundo o mesmo autor,

[...] essa orientação, que pretendeu resolver todos os problemas jurídicos nos limites exclusivos do Direito positivo e de sua interpretação, deu um tratamento exageradamente formal ao comportamento humano que seria definido como delituoso $[\ldots]$.

\footnotetext{
${ }^{1}$ BITTENCOURT, Cezar Roberto. Tratado de Direito Penal: Parte Geral 1. São Paulo. Saraiva, 2006.
} 
Nesta teoria são quatro os elementos estruturais: ação, com um conceito puramente descritivo, naturalista e causal, valorativamente neutro, preocupava-se apenas com o aspecto objetivo do alcance do resultado externo; tipicidade, representando o caráter externo da ação, compreendendo apenas os aspectos objetivos do fato descrito na lei; antijuricidade, enquanto elemento objetivo, formal e valorativo que recai na provocação de resultados externos negativos e indesejáveis juridicamente; culpabilidade, que era concebida como o aspecto subjetivo do crime, também tinha caráter descritivo, limitando-se a comprovar a existência de um vínculo subjetivo entre autor e fato.

O conceito neoclássico marca uma profunda revisão crítica e sistemática do conceito clássico, sem, contudo, abandonar completamente seus princípios fundamentais. Conforme Bittencourt,

[...] o conceito neoclássico corresponde à influência no campo jurídico da filosofia neokatiana, dando-se especial atenção ao normativo e axiológico. Foi substituída a coerência formal de um pensamento jurídico circunscrito em si mesmo por um conceito de delito voltado para os fins pretendidos pelo Direito Penal e pelas perspectivas valorativas que o embasam (teoria teleológica do delito) $[\ldots]^{2}$

Para esta nova doutrina, a ação, de acordo com $\mathrm{Neto}^{3}$, é examinada de forma bem mais ampla, trazendo, num primeiro momento, a ideia de manifestação exteriorizada da vontade. A tipicidade passou a reconhecer a existência dos elementos subjetivos do tipo, afastando definitivamente a concepção clássica do tipo, fundada em questões objetivas. A antijuridicidade passou a exigir determinada danosidade social, graduado, consequentemente, o injusto de acordo com a lesão produzida. A culpabilidade incorpora elementos da imputabilidade, dolo e culpa, e também a exigibilidade de conduta diversa para sua real configuração.

$\mathrm{Na}$ sequência da concepção neoclássica, surgiu o conceito finalista de delito. Segundo Neto $^{4}$, a teoria finalista lança a concepção da ação ao centro do debate, fazendo com que repercuta sobre todo o conteúdo da estrutura da teoria do delito. Welzel, principal teórico do finalismo, opunha-se ao conceito casual de ação, em especial, à separação entre vontade e seu conteúdo. A ação caminharia em direção a um acontecer real, ou seja, seria o exercício de uma atividade humana final, com o objetivo conscientemente fixado.

Bittencourt menciona que,

\footnotetext{
${ }^{2}$ BITTENCOURT, Cezar Roberto. Op. cit., p. 259.

${ }^{3}$ NETO, Félix Araújo. Op. cit.

${ }^{4}$ NETO, Félix Araújo. Op. cit.
} 
[...] com o finalismo, a teoria do delito encontra um dos mais importantes marcos de sua evolução.... a retirada de todos os elementos subjetivos que integravam a culpabilidade, nascendo, assim, uma concepção puramente normativa. 0 finalismo deslocou o dolo e a culpa para o injusto, retirando-os de sua tradicional localização - a culpabilidade - levando, dessa forma, a finalidade para o centro do injusto. Concentrou na culpabilidade somente aquelas circunstâncias que condicionam a reprovabilidade da conduta contrária ao Direito, e o objeto situa-se no injusto $[\ldots]^{5}$

Para $\mathrm{Neto}^{6}$, o finalismo rompe e rechaça por completo as concepções causalistas, que só valoram o objeto sensível enquanto efeito de um fator etiológico posto em movimento pelo agente.

\subsection{Conceito de crime}

Os crimes podem ser conceituados de acordo com o prisma formal, material e analítico.

O primeiro modo procura observar os seus aspectos externos, como bem expõe Fragoso, "seria toda ação ou omissão proibida pela lei, sob a ameaça de pena"”. 0 conceito formal busca descrever o crime através do imperativo legal vigente. Sendo, portanto, um conceito externo.

A ótica material, em consonância com Bittencourt, enxerga o crime como uma ação ou omissão que contraria os valores ou interesses de corpo social, exigindo sua proibição com a ameaça de pena ${ }^{8}$. Betiol bem explicou que crime seria qualquer fato lesivo a um interesse, cometido pelo homem, que possa comprometer as condições de existência, de conservação e de desenvolvimento da sociedade ${ }^{9}$. Quanto ao conteúdo, o crime é intrinsecamente vinculado à sociedade, a um fato social. Para Lobo,

[...] o crime é uma conduta praticada por um agente, que também é componente da sociedade e que agride, independentemente de quem que tenha sido sua vitima imediata, sujeitando-o a uma restrição em sua liberdade, amplamente considerada (pena, medida de segurança ou medida socioeducativa) $[\ldots]^{10}$

\footnotetext{
${ }_{6}^{5}$ BITTENCOURT, Cezar Roberto. Op. cit., p. 261.

${ }^{6}$ NETO, Félix Araújo. Op. cit.

${ }^{7}$ FRAGOSO, Heleno Cláudio. Lições de direito penal - A nova parte geral. 4. ed. Rio de Janeiro. Forense, 1994. p. 114

8 BITTENCOURT, Cezar Roberto. Op. cit.

9 BETTIOL, Giuseppe. Direito penale. Padova. Cedam, 1973, v.2.

10 LOBO, Silvana Lourenço. A Idade no Direito Penal Brasileiro da Menoridade. Belo Horizonte. Ed Madamentos, pg. 23.
} 
Segundo Bittencourt, os conceitos formal e material são insuficientes para permitir a análise dos elementos estruturais do conceito de crime $^{11}$. Diante disso, objetivando construir uma base mais completa, foi elaborado o conceito analítico. Em consonância com essa construção, ressaltando a depuração enfrentada ao longo dos anos, o crime seria uma ação ou omissão típica, antijurídica e culpável.

Enquanto a ação é atividade, a omissão seria a falta de ação, falta que é uma transgressão a uma expectativa jurídica sobre um ato considerado imperativo e necessário. Conduta típica é a correspondência entre o fato e o modelo abstrato (previsão legislativa), ou seja, conduta humana que causa resultado tipicamente previsto na lei. A antijuridicidade (ilicitude), conforme Lobo é o antagonismo existente entre a finalidade do Direito e do próprio Direito Penal, que é o bem comum e a conduta livre, consciente e finalísticamente realizada pelo agente, contrariando o Direito ${ }^{12}$. Ou seja, sempre que a conduta é típica e não estão presentes os excludentes de ilicitude, quer dizer a legítima defesa, o estado de necessidade e o estrito cumprimento de dever legal e o exercício regular de direito, conforme art. 19 do Código Penal restará configurada a ação ilícita.

A culpabilidade, por sua vez, é a medida de reprovação merecida pelo agente que praticou o fato típico e ilícito por sua conduta, ou seja, é juízo de reprovação social sobre a ação ou omissão, pois, quando era esperado que o sujeito tomasse uma determinada atitude, toma outra proibida em seu lugar. Todavia, é importante ressaltar que a conduta, apesar de ser vedada pelo ordenamento, não é reprovável quando o sujeito não é imputável, quando não tem potencial consciência da ilicitude ou quando dele não se poderia exigir do indivíduo conduta diversa.

\subsection{A infração}

Depois de fazer essa digressão histórica pelos fundamentos que deram origem à atual concepção de crime, cabe agora trazer a ideia do delito aplicada aos adolescentes, para que evidenciar a diferença a conceitual entre o crime, anteriormente trabalhado, e a infração, delito cometido por crianças e adolescentes.

\footnotetext{
${ }^{11}$ BITTENCOURT, Cezar Roberto. Op. cit.

${ }^{12}$ LOBO, Silvana Lourenço. Op. cit.
} 
REDUČ̃̃O DA MAIORIDADE PENAL: DISCUSSÃO ACERCA DESSA PROPAGADA SOLUÇÃO PARA REDUÇÃO DA CRIMINALIDADE JUVENIL

Diego Mendes de Sousa, letícia Cancela de Oliveira, luiza Hermeto COUITINHO CAMPOS

$\mathrm{O}$ ato infracional, de acordo com o art. 103 do Estatuto da Criança e do Adolescente, é a conduta praticada pelo adolescente ou pela criança, que está descrita como crime ou contravenção penal ${ }^{13}$.

Daquele conceito tripartido de crime (conduta típica, ilícita e culpável) apresentado, podemos extrair que o adolescente praticante de conduta delituosa estará incidindo numa ação ou omissão típica, uma vez que é prevista como penalmente relevante no ordenamento jurídico brasileiro, ilícita, pois contraria aos preceitos normativos vigentes. Entretanto não será culpável, pois o ordenamento jurídico estabelece a menoridade como quesito excludente de culpabilidade. Dessa forma o adolescente praticará uma ação típica, ilícita, mas não culpável, de acordo com o Código Penal.

\section{MAIORIDADE PENAL: CONCEITOS, CRITÉRIOS E EVOLUÇÃO HISTÓRICA}

Conforme art. 27 do atual Código Penal brasileiro, "Os menores de dezoito anos são penalmente inimputáveis, ficando sujeitos às normas estabelecidas na legislação especial”. Portanto, o direito pátrio, no dispositivo em questão, adotou um critério puramente biológico, de idade do autor do fato, não se levando em conta o desenvolvimento mental do adolescente (critério psicológico ou biopsicológico $)^{14}$, que não está sujeito à sanção penal ainda que plenamente capaz de entender o caráter ilícito do fato e de determinar-se de acordo com esse entendimento. Trata-se de uma presunção absoluta de inimputabilidade que faz com que o menor seja considerado como tendo desenvolvimento mental incompleto em decorrência de um

13 Contravenções penais são infrações consideradas de menor potencial ofensivo que muitas pessoas acabam cometendo no dia a dia, que chegam até a ser toleradas pela sociedade e até por autoridades, mas que não podem deixar de receber a devida punição. É evidente que por serem delitos de menor gravidade recebem penas proporcionais. As contravenções penais estão previstas no Decreto-lei $\mathrm{n}^{\circ}$ $3.688 / 41$.

14،a) Sistema biológico: é observada exclusivamente a característica física do agente, independentemente de sua capacidade psicológica; ou seja, é observada a idade cronológica, exclusivamente contada em anos, independentemente da capacidade mental.

b) Sistema psicológico: é observada apenas a capacidade de entender do agente (o seu discernimento sobre a capacidade de realização de conduta delituosa), independentemente de qualquer característica física pessoal; ou seja observa-se a capacidade da idade mental, e não a idade cronológica no caso dos menores de 18 anos.

c) Sistema biopsicológico: são observados ambos os aspectos descritos. Observam-se tanto as condições puramente físicas do agente quanto suas características psicológicas de discernimento sobre os atos que está cometendo (idade mental e cronológica)." LOBO, Silvana Lourenço. Op. Cit., p. 34. 
critério de política criminal. Implicitamente, conforme Mirabete ${ }^{15}$, "a lei estabelece que 0 menor de 18 anos não é capaz de entender as normas da vida social e de agir conforme esse entendimento".

A regra foi elevada a nível constitucional, prevendo-se expressamente a inimputabilidade dos menores de 18 anos (art. 228 da CF). Mesmo a maioridade civil alcançada antes dos 18 anos não torna o sujeito imputável.

\subsection{Maioridade penal: evolução histórica}

\subsubsection{Período Colonial}

De acordo com Queiroz ${ }^{16}$, desde o surgimento das primeiras leis penais até o início do século XX, as crianças eram tratadas praticamente iguais aos adultos, com relação à responsabilidade penal. Vigorava, à época, o pensamento medieval sobre as crianças, não existindo a concepção da vida infantil como um período diferenciado da vida adulta, o que, apenas ocorre, em meados do século XX.

Segundo Saraiva ${ }^{17}$, as primeiras normas atinentes a responsabilidade penal no Brasil foram as Ordenações Afonsinas de 1446, Manuelinas de 1521 e Filipinas de 1603, editadas em Portugal.

As ordenações Filipinas foram, conforme Queiroz, as únicas a terem efetividade, regulando em seu capítulo $\mathrm{V}$, os crimes e as punições, além da particular situação dos menores. Este ordenamento estabelecia gradações e distinções na punição para os indivíduos com até 21 anos incompletos.

Nas ordenações em questão, os menores de 7 anos eram considerados absolutamente incapazes, e seus atos equiparados aos dos animais. Os jovens entre 7 e 17 anos tinham o privilegio de não serem condenados à pena capital, subsistindo todas as outras, inclusive a custódia em estabelecimento prisional comum. Os jovens entre 17 e 20 anos, gozavam de uma

\footnotetext{
${ }^{15}$ MIRABETTE, Julio Fabbrini. Manual de Direito, volume I: parte geral, arts. 1 a 120 do Codigo Penal, 2010. São Paulo.

${ }^{16}$ QUEIROZ, Bruno Caldeira Marinho de. Evolução Histórico Normativa da Proteção e Responsabilização Penal Juvenil no Brasil. Disponível http://artigos.netsaber.com.br/resumo_artigo_6912/artigo_sobre_evolucao_historiconormativa_da_protecao_e_responsabilizacao_penal_juvenil_no_brasil. Acesso em: 12/10/2011.

17 SARAIVA, João Batista Costa. Adolescente em Conflito com a Lei - da indiferença à proteção integral: uma abordagem sobre a responsabilidade penal juvenil. 1 ed. Porto Alegre: Livraria do Advogado, 2003, p.32.
} 
diminuição da pena em 1/3 em relação aos adultos, de acordo com o juízo do magistrado, tendo-se três critérios objetivos: a) modo como o delito foi praticado; b) suas circunstâncias; c) a pessoa do menor. E um critério subjetivo: a) malícia da ação.

\subsubsection{Período Imperial}

O Código Criminal de 1830, nova legislação do Brasil recém proclamada independente, traz mudanças importantes relativo à imputação penal a crianças e adolescentes. Queiroz cita o estabelecimento de uma inimputabilidade penal relativa aos jovens entre 7 e 14 anos, em que tais jovens só não seriam responsabilizados se o magistrado verificasse que não agiram com discernimento, sem aptidão para distinguir o bem do mal. 0 citado autor ainda aponta o recolhimento destes jovens em casa de correção, não mais nos estabelecimentos para adulto, como disposto nas ordenações Filipinas. Sem esquecer-se de mencionar o limite para recolhimento de 17 anos.

\subsubsection{Período Republicano}

Com a proclamação de republica em 1989 tem-se a necessidade de criar instrumentos que se adequassem à nova realidade do Brasil, instrumentos que, em alguma medida, rompessem com o passado imperial. Para tanto, em termos penais, foi implementado o Código Penal de 1890 , que torna mais robusta a temática da imputabilidade de crianças e adolescentes. Eleva-se a imputabilidade para os 9 anos, sendo que os jovens entre 9 e 14 anos, gozariam de imputabilidade relativa, mantendo-se a avaliação do magistrado sobre seu discernimento.

Mas foi a partir do século XX que o Brasil, de fato, se viu forçado a enfrentar a questão do menor infrator. Segundo Oliveira ${ }^{18}$ isso se deu, principalmente, devido ao crescente desenvolvimento das indústrias, a urbanização e o trabalho assalariado das mulheres, que, tendo que sustentar os lares, deixaram de cuidar exclusivamente da educação dos filhos, culminando em uma instabilidade e degradação dos valores dos menores, resultado em práticas delituosas.

${ }^{18}$ OLIVEIRA, Raimundo Luiz Queiroga de. O Menor Infrator e a Eficácia das Medidas Sócio-Educativas. Disponível em: <http://jus2.uol.com.br/doutrina/texto.asp?id=4584>. Acesso em: 12 out. 2011. 
REDUČ̃̃O DA MAIORIDADE PENAL: DISCUSSÃO ACERCA DESSA PROPAGADA SOLUÇÃO PARA REDUÇÃO DA CRIMINALIDADE JUVENIL

Diego Mendes de Sousa, letícia Cancela de Oliveira, luiza Hermeto COUITINHO CAMPOS

O início do século XX foi marcado, conforme Saraiva ${ }^{19}$, por crescentes críticas à política criminal adotada pelo Código Republicano, em virtude da reduzida idade de inimputabilidade penal e a impropriedade da expressão “discernimento”. Dando vazão a essa discussão, a Lei Orçamentária - Lei $n^{\circ} 4.242$ de janeiro de 1921 - tratando, já por motivos de política criminal e de natureza criminológica, de forma diversa a questão da imputabilidade penal, em seu art. $3^{\circ}$, parágrafo 17, estabeleceu a inimputabilidade penal absoluta ao menor de 14 anos, impondo, como salienta Queiroz, um critério puramente objetivo de imputabilidade penal, abandonando o sistema biopsicológico em vigor até então. De acordo com esta norma, os menores de 14 anos seriam inimputáveis, ao passo que jovens entre 14 e 18 anos seriam submetidos a um processo especial, diferenciado do aplicável aos adultos. Posteriormente, o Decreto 22.213, conhecido como Consolidação das Leis Penais reafirma a citada disposição.

Em 1927, edita-se o decreto 17.943-A, o $1^{\circ}$ Código de Menores do Brasil, ou como ficou conhecido, Código Melo Matos. Este reafirmou, no que diz respeito à imputabilidade penal, mais uma vez, os itens contidos na Lei de 1921.

Com o Estado Novo de Getúlio Vargas foi editado um novo Código Penal. O que se esperava, conforme Queiroz era o endurecimento da lei penal no que toca à responsabilidade penal de crianças e adolescentes, seguindo a tendência de um ambiente ditatorial vigente. Contudo, o que se verificou foi o oposto, a nova normativa estabeleceu a maioridade aos 18 anos e consolidou o critério biológico. Dessa forma, quando um menor pratica um fato descrito como crime ou contravenção penal, a legislação adotou a presunção absoluta da falta de discernimento do indivíduo menor de 18 anos.

De acordo com Oliveira ${ }^{20}$, o Código Penal de 1940, em consonância o normativas anteriores, qualquer que seja a idade do menor, este não estaria submetido a processo criminal, mas a procedimento previsto em legislação especial.

\subsubsection{Período Pós $2^{\mathrm{a}}$ Guerra}

\footnotetext{
${ }^{19}$ SARAIVA, João Batista Costa. Adolescente em Conflito com a Lei - da indiferença à proteção integral: uma abordagem sobre a responsabilidade penal juvenil. Porto Alegre: Livraria do Advogado, 2003. p. 50. 20 OLIVEIRA, Raimundo Luiz Queiroga de. O Menor Infrator e a Eficácia das Medidas Sócio-Educativas. Disponível em: <http://jus2.uol.com.br/doutrina/texto.asp?id=4584>. Acesso em: 12 out. 2011.
} 
REDUÇÃO DA MAIORIDADE PENAL: DISCUSSÃO ACERCA DESSA PROPAGADA SOLUÇÃO PARA REDUÇÃO DA CRIMINALIDADE JUVENIL

A imputabilidade penal de crianças e adolescentes sofreu algumas alterações durante o período do Regime Militar. O Decreto-Lei 1004/69, que institui o Código Penal de 1969, possibilitou a imposição de $1 / 3$ a $1 / 2$ das penas impostas a adultos, aos jovens delinquentes. Além disso, Saraiva ${ }^{21}$ ressalta que o Código Penal Militar fixou a imputabilidade penal, frente a crimes militares, em 16 anos, preceito que só veio a ser revogado pela Constituição de 1988.

Até a promulgação da Constituição Federal de 1988, alguns diplomas legais foram implementados, como o $2^{\circ}$ Código de Menores do Brasil - Lei $n^{\circ}$ 6.697/79 -, Lei $n^{\circ} 7.209 / 84$, que deu nova redação à Parte Geral do Código Penal 1940, ambas conservaram as disposições do Código do Estado Novo.

Em consonância com passagem anterior, a Constituição Federal de 1988 corroborou, em seu art. 228 , os artigos. $1^{\circ}$, inciso II e 41 , $\S 3^{\circ}$ do $2^{\circ}$ Código de Menores, vigente ainda à época, no sentido da inimputabilidade penal dos menores de dezoito anos. Segundo o citado art. 228, "são penalmente inimputáveis os menores de dezoito anos, sujeitos às normas da legislação especial".

O Estatuto da Criança e do Adolescente (ECA), instituído pela Lei 8.069 de 1990, portanto, dois anos após a proclamação da Constituição de 1988, foi um marco em termos de legislação infanto-juvenil. Como versa Lair Loureiro em apelação criminal,

[...] concebido como uma legislação moderna e realista, objetivou dar cumprimento e proteção integral aos direitos fundamentais da criança e do adolescente, assim assegurados na Constituição da República. Bem por isso e visando assegurar, com absoluta prioridade, a efetivação desses direitos, o Estatuto atribuiu essa tarefa, como assim vem disposto em seu art. $4^{\circ}$, à família, à comunidade, à sociedade em geral e ao próprio Poder Público. Para tanto, simplificou formas e procedimentos, garantiu e facilitou o acesso dos hipossuficientes à Justiça menorista, sempre com o intuito de tornar efetiva aquela proteção integral à criança e ao adolescente, assim reiterada logo no art. $1^{\circ}$, do Estatuto referido [.... ${ }^{22}$

Entretanto cabe ressaltar, com relação à imputabilidade penal de crianças e adolescentes, objeto deste estudo, que a normativa em questão não inovou, uma vez que a Carta Constitucional já havia estabelecido os princípios básicos da garantia de direitos da criança e do adolescente. Dito isso, cabe frisar que coube ao art. 104 do ECA replicar conteúdo

\footnotetext{
${ }^{21}$ SARAIVA, João Batista Costa. Adolescente em Conflito com a Lei - da indiferença à proteção integral: uma abordagem sobre a responsabilidade penal juvenil. Porto Alegre: Livraria do Advogado, 2003. p. 30.

22 LOUREIRO, Lair. in LOBO, Silvana Lourenço. Op. Cit., p. 75.
} 
REDUČ̃̃O DA MAIORIDADE PENAL: DISCUSSÃO ACERCA DESSA PROPAGADA SOLUÇÃO PARA REDUÇÃO DA CRIMINALIDADE JUVENIL

disposto no texto constitucional dispondo acerca da inimputabilidade dos menores de 18 (dezoito) anos.

\section{POSIÇÕES DOUTRINÁRIAS}

\subsection{Favoráveis à Redução da Maioridade Penal}

Lobo cita que Nélson Hungria, de certa forma, “era favorável à diminuição da idade penal para 16 anos" $^{\prime 23}$. Segundo ele, "alguns jovens de 16 anos possuem capacidade para responder por seus atos, inclusive os criminosos, devendo ser imputáveis" ${ }^{24}$. Ainda segundo Hungria, “a imputabilidade fixada aos 16 anos aumentaria a consciência da responsabilidade social dos jovens” 25 . Lobo ainda traz o posicionamento de Paulo José da Costa Júnior. Segundo este,

[...] As condições sociais de 1940, quando se estabeleceu a presunção retro, não são aplicadas mais as de hoje. Tudo mudou de forma radical: as condições sociais, possibilitando novas condutas permissivas; os meios de comunicação de massa, ensejando ao jovem conhecer muito antes o mundo. Por via de consequência, o pressuposto biológico atual não será mais o mesmo. 0 jovem de hoje, aos dezesseis anos, tem plena capacidade para entender o caráter ilícito do fato. Como então insistir em estabelecer dezoito anos o limite mínimo da imputabilidade penal? $[\ldots]^{26}$

Segundo Pereira ${ }^{27}$, diversas entidades e organizações vêm somando forças objetivando reduzir a idade penal, sob o argumento da excessiva elevação do número de crimes praticados por menores de 18 anos. Cabe ressaltar, conforme o próprio autor que este é o argumento que mais encontra eco no meio jurídico e também junto à população.

Outro argumento frequentemente utilizado é ligado à eficácia do ECA. Devido a uma suposta falha, por não punir com a desejável medida, os delitos praticados pelos adolescentes infratores. Assim, seria o Estatuto, um instrumento brando, condescendente e que estimularia a prática criminosa. De acordo com Joelma Simonetti,

\footnotetext{
${ }^{23}$ LOBO, Silvana Lourenço. Op. cit., p. 68.

${ }^{24}$ HUNGRIA, Nélson. Comentários ao Código Penal. Rio de Janeiro: Forense. 1958, v. I, , p. 359.

${ }^{25}$ HUNGRIA, Nélson. Op. Cit., p. 351.

${ }^{26}$ COSTA JÚNIOR, Paulo José. Curso de direito penal - Parte geral. São Paulo: Saraiva, 1992, v 1, p.101.

${ }^{27}$ PEREIRA, João Batista Costa. A Maioridade: Uma Visão Interdisciplinar. Jus Navigandi, Teresina, ano 7, n. 60, nov. 2002. Disponível em: <http://jus2.uol.com.br/doutrina/texto.asp?id=3491>. Acesso em: 12 out. 2011.
} 
REDUČ̃̃O DA MAIORIDADE PENAL: DISCUSSÃO ACERCA DESSA PROPAGADA SOLUÇÃO PARA REDUÇÃO DA CRIMINALIDADE JUVENIL

[...] a pena que se aplica em casos extremos é a internação em instituições apropriadas por um período de, no máximo, 3 anos, a partir do que o infrator passa a ser encarado sem nenhuma restrição, ou seja, sem antecedentes, não importando a gravidade do crime praticado $[\ldots]^{28}$

Para Cavallieri,

[...] A manutenção da idade de 18 anos para o afastamento do menor, criança e adolescente, do Código Penal é uma bandeira de todos, menoristas e estatutistas. [...]. Quando lutamos pela conservação dessa idade, é comum ouvirse, até de pessoas cultas, a afirmação de que ela é absurda, 'porque, mesmo com muito menos de 18 anos eles [sic] sabem o que fazem.' Não thes ocorre que o conhecimento está ligado à imputabilidade e que, quando os doutos afirmam que os menores de 18 são inimputáveis, querem dizer que se trata de presunção [sic] de inimputabilidade. Mas, porque falar-se em presunção, se temos a realidade? É obvio que a partir de tenra idade, eles sabem o que fazem. [...]. Toda esta dúvida tem sua origem na Exposição de Motivos do Código Penal de 1940, quando o Ministro Francisco Campos escreveu que os menores ficavam fora daquela lei, porque eram imaturos [sic]. [...]. Segundo ele, todos os menores de 18 anos no Brasil eram imaturos. Absurdo completo. E nós contaminamos toda a nação com esta insólita concepção. Espero que a importância prática de uma conceituação adequada tenha sido demonstrada. Os estatutistas merecem todos os encômios pela elevação à Lei Magna de uma aspiração comum, mas poderiam ter aproveitado para destruir um mito prejudicial. Eles [sic] sabem o que fazem, mas não vão para a cadeia, pois temos solução melhor para seus crimes $[\ldots]^{29}$

Dando vazão ao anseio de parcela considerável da população, várias emendas constitucionais foram propostas com objetivo de reduzir a idade penal. Como relata Lobo, as Emendas Constitucionais n. 14-A, de 1989, do deputado Telmo Kirst; 98, de 1992, do deputado Sólon Borges dos Reis; 386, de 1996, do deputado Pedrinho Abrão; 20, de 1999, senador Romero Jucá e José Roberto Arruda; 26, de 2002, do senador Íris Rezende; 9, de 2004, do senador Papaléo Paes ${ }^{30}$. Todas essas emendas tinham como objetivo reduzir para 16 anos a imputabilidade, distinguindo-se a emenda proposta pelo deputado Pedrinho Abrão que sugeria o critério biopsicológico, entre os 16 e 18 anos, para os crimes contra pessoa e o patrimônio, assim como os crimes hediondos.

${ }^{28}$ SIMONETTI, Joelma. Menoridade Penal: existe impunibilidade ? Disponível em: http://www.ambitojuridico.com.br/site/index.php?n_link=revista_artigos_leitura\&tartigo_id=2412. Acesso em 30 de out. 2011. ${ }_{29}$ CAVALLIERI, Alyrio. Falhas do Estatuto da Criança e do Adolescente. Rio de Janeiro: Forense, 1997, p. 54-56.

${ }^{30}$ LOBO, Silvana Lourenço. Op. cit., p. 59. 
REDUÇÃO DA MAIORIDADE PENAL: DISCUSSÃO ACERCA DESSA PROPAGADA SOLUÇÃO PARA REDUÇÃO DA CRIMINALIDADE JUVENIL

\subsection{Contrárias à Redução da Maioridade Penal}

Saraiva $^{31}$, inicialmente, prega uma clara diferenciação entre inimputabilidade e impunidade. Segundo ele,

[...] A circunstância de o adolescente não responder por seus atos delituosos perante a Corte Penal não o faz irresponsável. Ao contrário do que a sofismática e erroneamente se propala, o sistema legal implantado pelo Estatuto da Criança e do Adolescente faz estes jovens, entre 12 e 18 anos, sujeitos de direitos e de responsabilidades e, em caso de infração, prevê medidas socioeducativas, inclusive com a privação de liberdade $[\ldots]^{32}$

Complementando este raciocínio, Cuneo ${ }^{33}$, afirma a necessidade de derrubar o mito da inimputabilidade/impunidade, pois o adolescente entre 12 e 18 anos é imputável perante a legislação própria, tendo responsabilidade estatutária, inobstante sua responsabilização possua caráter pedagógico.

Para Saraiva, o Estatuto prevê e sanciona medidas socioeducativas eficazes, reconhece a possibilidade de privação provisória de liberdade ao infrator, não sentenciado, inclusive em parâmetros mais abrangentes que o CPP refere aos imputáveis na prisão preventiva. 0 autor em questão ainda faz uma comparação entre os 3 anos previsto para medida de internação no ECA e o cumprimento de pena submetida aos adultos. Segundo ele,

[...] Deve-se considerar, por exemplo, que, para um adulto permanecer três anos "fechado", sem nenhuma perspectiva de atividade externa, sua pena deverá situar-se em módulo não inferior a dezoito anos de reclusão, eis que, cumpridos $1 / 6$ da pena ( que são os três anos a que se sujeita o adolescente), terá direito a beneficio $[\ldots]^{34}$

Corroborando isto, Cuneo, afirma,

[...] em parâmetros semelhantes ao que o Código de Processo Penal destina aos maiores de dezoito anos, ao contrário do que se imagina, um adolescente que pratica, por exemplo, um roubo a mão armada (juntamente com um indivíduo adulto), é primário e tem bons antecedentes, poderá permanecer até três anos em regime de internação, com progressão para semiliberdade por igual período e ainda mais três anos em liberdade assistida, se ainda não recomendável seu

\footnotetext{
31 SARAIVA, João Batista Costa. A Idade e as Razões: Não ao Rebaixamento da Imputabilidade Penal, in Idade da Responsabilidade Penal. Belo Horizonte, 2003.

32 SARAIVA, João Batista Costa. Op. cit., p. 52.

${ }^{33}$ CUNEO, Mônica Rodrigues. Inimputabilidade não é Impunidade: Derrube este Mito, Diga não à Redução da Idade Penal, in Idade da Responsabilidade Penal. Belo Horizonte, 2003.

. ${ }^{34}$ SARAIVA, João Batista Costa. Op. Cit., p. 57.
} 
REDUČ̃̃O DA MAIORIDADE PENAL: DISCUSSÃO ACERCA DESSA PROPAGADA SOLUÇÃO PARA REDUÇÃO DA CRIMINALIDADE JUVENIL

Diego Mendes de Sousa, letícia Cancela de Oliveira, luiza Hermeto COUITINHO CAMPOS

integral retorno à vida em sociedade, enquanto o imputável, apenado em cinco anos e quatro meses de reclusão, cumprindo um/terço (aproximadamente dois anos), terá restabelecida sua liberdade $[\ldots]^{35}$

Procurando rebater a ideia do discernimento quanto ao cometimento do ato delituoso, Nunes expõe que,

[...] Justifica-se a maioridade aos dezoito anos, não pela questão de ter o não o adolescente discernimento, mas sim pela forma de punição que the será imposta. Se o indivíduo ainda não tem personalidade formada, é mais do que coerente que se the imponha tratamento diferenciado. Nada soa mais brutal do que encarcerar jovens impúberes com criminosos reconhecidamente periculosos $[\ldots]^{36}$

Para Nunes, concluindo sua tese, o ponto central da questão não está no antecedente (discernimento), está no consequente (punição).

Munir Cury $^{37}$ enxerga o limite de 18 anos fixado pela legislação pátria como fruto de uma política criminal de Estado, portanto, em nada estaria vinculada com a capacidade ou incapacidade de entendimento. Segundo ele,

[...] É claro que o jovem e mesmo a criança têm o necessário discernimento, sendo ambos capazes de perceber que é reprovado furtar, danificar, matar, e não se submetem às regras penais, não só porque a Criminologia concluiu resultar inconveniente aos próprios fins de prevenção e repressão da criminalidade submetê-los ao sistema reservado aos adultos, como e sobretudo pelo fato de a Política Criminal, considerando a falência do sistema carcerário, propor como alternativa ao método rígido das penas criminais um sistema flexível de medidas protetivas e/ou socioeducativas, capazes, conforme o caso, de proteger, educar, e até punir, prevenindo práticas anti-sociais $[\ldots]^{38}$

Conforme expõe Cuneo, reduzir a imputabilidade seria uma medida que não contribuirá para a diminuição do incremento da criminalidade, nem a curto, médio ou longo prazo, se configurando, na verdade, com reação repressiva simplista, em nada prevenindo a delinquência.

Complementando esta ideia, Saraiva afirma que a proposta reducionista, ao contrário de configurar-se como avanço, vem na contramão da história, pois o tratamento dispensado à

\footnotetext{
${ }^{35}$ CUNEO, Mônica Rodrigues. Op. cit., p.73.

${ }^{36}$ NUNES, Francisco Clávio Saraiva. Redução da Maioridade Penal: Uma Peseudo-Solucao. in Idade da Responsabilidade Penal. Belo Horizonte, 2003. p. 36.

${ }^{37}$ CURY, Munir. Reduzir a Idade Penal não é Solução. in Idade da Responsabilidade Penal. Belo Horizonte, 2003.
}

${ }^{38}$ CURY, Munir. Op. cit. p. 84. 
matéria pela legislação nacional se em consonância com a Declaração Universal de Direitos da Criança.

\section{MAIORIDADE PENAL PELO MUNDO}

Muito se compara a imputabilidade penal brasileira à praticada nos demais países do mundo para se justificar a redução da maioridade. Essa comparação surge, pois se tem em mente que em boa parte do mundo a imputabilidade penal é demasiadamente menor do que a praticada no Brasil. A seguir, tabela $1^{39}$, exporá um comparativo da imputabilidade penal em diversos países do mundo, com a idade da responsabilidade juvenil e maioridade da idade penal. Foram selecionados países ditos de mais avançados do ponto de vista econômico e jurídico e outros com realidade social e localização geográfica mais aproximada ao Brasil.

TABELA 1 - RESPONSABILIDADE JUVENIL E ADULTA NO MUNDO

\begin{tabular}{|c|c|c|}
\hline País & $\begin{array}{c}\text { Idade da } \\
\text { Responsabilidade Penal } \\
\text { Juvenil (anos) }\end{array}$ & $\begin{array}{c}\text { Maioridade da } \\
\text { Idade Penal } \\
\text { (anos) }\end{array}$ \\
\hline Alemanha & 14 & $18-21$ \\
\hline Argentina & 12 & 18 ou mais \\
\hline Canadá & $12-17$ & 18 ou mais \\
\hline Chile & 17 ou menos & $18-21$ \\
\hline Dinamarca & $15-17$ & $18-21$ \\
\hline Espanha & 12 & 18 \\
\hline França & 13 & \\
\hline
\end{tabular}

${ }^{39}$ Esta tabela foi elaborada a partir de conteúdos dispostos no livro "Crime e a Maioridade Penal de Brasil - Contribuindo para o debate com a Quebra de Mitos", de Mário Felizardo. Disponível em: www.promenino.org.br/Portals/0/Biblioteca; Artigo "Redução da maioridade penal: Delinquencia juvenil se resolve aumentando oportunidades e não reduzindo idade penal", de Túlio Kahn. Disponível em: www.nossacasa.net/recomeco/0069.htm. Acessos em 20/10/2010. Ambos os trabalhos citam a United Nations Survey os Crime Trends and Operations of Criminal Justice realizada pelo órgão Office on Drug and Crime da ONU - Organização das Nações Unidas, dos anos de 2003 e 2004, como fontes. 


\begin{tabular}{|c|c|c|}
\hline Itália & 14 & 18 \\
\hline Holanda & $12-17$ & 18 \\
\hline Japão & 20 ou menos & 21 \\
\hline Noruega & $15-17$ & $18-21$ \\
\hline Peru & 17 ou menos & 18 \\
\hline Portugal & 15 ou menos & $16-21$ \\
\hline $\begin{array}{l}\text { Reino } \\
\text { Unido }\end{array}$ & $7-18$ & 18 \\
\hline Suécia & $15-17$ & $18-21$ \\
\hline Uruguai & 17 ou menos & 18 \\
\hline Venezuela & 17 ou menos & 18 \\
\hline
\end{tabular}

É interessante observar Alemanha, Dinamarca, Espanha, Noruega e Suécia. Todos esses países estabelecem a maioridade penal aos 18 anos, como se pratica no Brasil. Contudo, fixam ainda uma faixa (18-21) em que os denominados “jovens-adultos” cumprirão as reprimendas judiciais em modo diferenciados dos comparados aos demais adultos, em estabelecimentos penais apartados e por períodos relativamente inferiores.

Em Portugal, a maioridade penal ocorre aos 16 anos, entretanto a lei reserva aos jovens, entre 16 e 21 anos, tratamento diferenciado em relação aos demais. Conforme dispõe o art. $9^{\circ}$ do Código Penal Português, "aos maiores de 16 anos e menores de 21 são aplicáveis normas fixadas em legislação especial” ${ }^{40}$. Estes jovens, entre outras coisas, em consonância com a Lei $n^{\circ}$ $401 / 82$, de 23 de setembro de $1982^{41}$, recebem uma dosagem diferenciada de pena e são acautelados em estabelecimentos de internação diferenciados.

No Japão a imputabilidade penal se dá a partir dos 21 anos, acima do praticado no Brasil.

40 Código Penal Português. Disponível em: http://www.portolegal.com/CPENAL.htm. Acesso em 20/10/2011.

41 A Lei $n^{\circ}$ 401/82 de 23 de setembro institui, conforme determina o Código Penal Português, o regime especial de pena aplicável aos denominados "jovens delinqüentes" (idade entre 16 e 21 anos). Disponível em http://www.pgdlisboa.pt/pgdl/leis/lei_mostra_articulado.php?nid=226\&tabela=leis\&nversao=. Acesso em 26/10/2010. 
Em países vizinhos, como Chile, Peru, Uruguai e Venezuela, tem-se disciplina idêntica à praticada internamente. Destoa a Argentina, com imputabilidade aos 16 anos.

Diante deste comparativo tem-se claramente que os limites impostos pela legislação brasileira, no que diz respeito à imputabilidade penal, está em consonância com boa parte do que se aplica em legislações alienígenas, ao contrário do que se propaga. Inclusive cabe salientar que nesta primeira década do novo milênio, nações como Alemanha e Espanha, empreenderam reforma em seus diplomas legais objetivando criar um sistema especial para jovens na faixa de 18 a 21 anos. ${ }^{42}$

\section{INCIDÊNCIA INFRACIONAL INFANTO JUVENIL EM BELO HORIZONTE}

Outra questão corriqueira no debate atinente à redução da maioridade penal diz respeito ao alegado recrudescimento dos atos cometidos por adolescentes. Segundo muitos defensores da propagada redução, ela se justifica na medida em que cada vez mais adolescentes têm incidido no cometimento de atos infracionais de grave potencial, notadamente homicídios. A tabela $2^{43}$ exibe a natureza dos atos infracional cometido adolescentes na Comarca de Belo Horizonte nos anos de 2009 e 2010.

TABELA 2 - INCIDÊNCIA INFRACIONAL INFANTO-JUVENIL NA COMARCA DE BELO HORIZONTE

\begin{tabular}{|c|c|c|c|c|}
\hline ATO INFRACIONAL & \multicolumn{2}{|c|}{ OCORRÊNCIAS 2009 } & \multicolumn{2}{c|}{ OCORRÊNCIAS 2010 } \\
\hline & $\mathbf{N}$ & $\%$ & $\mathbf{N}$ & $\%$ \\
\hline $\begin{array}{c}\text { PERIGO PARA A VIDA OU SAÚDE DE } \\
\text { OUTRO }\end{array}$ & 20 & 0,2 & - & 0 \\
\hline EXTORSÃO & 7 & 0,1 & 1 & 0 \\
\hline FALSIFICAÇÃO DE DOCUMENTOS & 18 & 0,2 & 4 & 0 \\
\hline DANO & 444 & 4,9 & 283 & 3 \\
\hline HOMICÍDIO & 41 & 0,5 & 32 & 0,3 \\
\hline LESÃO CORPORAL & 750 & 8,3 & 627 & 6,7 \\
\hline ESTUPRO & 26 & 0,3 & 23 & 0,2 \\
\hline FURTO & 1125 & 12,5 & 1055 & 11,3 \\
\hline ROUBO & 848 & 9,4 & 819 & 8,8 \\
\hline POSSE OU PORTE ILEGAL DE & 395 & 4,4 & 385 & 4,1 \\
\hline ARMAS & & & &
\end{tabular}

42 Kahn, Túlio. "Redução da maioridade penal: Delinqüência juvenil se resolve aumentando oportunidades e não reduzindo idade penal". Disponível em: www.nossacasa.net/recomeco/0069.htm. Acesso em: 20/10/2011.

43 Tabela retirada do www.tjmg.jus.br/ciabh e www.defesasocial.mg.gov.br/socioeducativo no dia 10/10/2011. 


\begin{tabular}{|c|c|c|c|c|}
\hline POSSE PARA USO DE DROGAS & 1901 & 21,1 & 1862 & 20 \\
\hline LATROCÍNIO & 4 & 0 & 4 & 0 \\
\hline ESTELIONATO & 9 & 0,1 & 9 & 0,1 \\
\hline DESACATO/ DESOBEDIÊNCIA & 193 & 2,1 & 193 & 2,1 \\
\hline INFRAÇÃO DE TRÂNSITO & 196 & 2,2 & 198 & 2,1 \\
\hline AMEAÇA & 391 & 4,3 & 395 & 4,2 \\
\hline VIAS DE FATO/ RIXA & 318 & 3,5 & 390 & 4,2 \\
\hline TRÁFICO DE DROGAS & 1871 & 20,8 & 2362 & 25,4 \\
\hline TENTATIVA DE HOMICÍDIO & 19 & 0,2 & 24 & 0,3 \\
\hline SEQUESTRO & 3 & 0 & 6 & 0,1 \\
\hline PICHAÇÃO & 118 & 1,3 & 240 & 2,6 \\
\hline RECEPTAÇÃO & 47 & 0,5 & 97 & 1 \\
\hline VIOLAÇÃO DE DIREITOS AUTORAIS & 3 & 0 & 40 & 0,4 \\
\hline OUTROS & 267 & 3 & 268 & 2,9 \\
\hline TOTAL VÁLIDO & $\mathbf{9 0 1 4}$ & $\mathbf{1 0 0}$ & $\mathbf{9 3 1 7}$ & $\mathbf{1 0 0}$ \\
\hline TOTAL GERAL & $\mathbf{9 6 4 5}$ & & $\mathbf{9 8 8 3}$ & \\
\hline & & & &
\end{tabular}

Da análise da tabela acima podemos retirar, entre outras coisas, que, homicídio consumado e tentado respondem a $0,7 \%$ dos atos cometidos. Roubo corresponde a algo em torno do $9 \%$ nos 2 anos abrangidos pela análise. Dessa forma podemos perceber, a partir da realidade de Belo Horizonte, que infrações com grave potencial ofensivo constituem exceções nas práticas perpetradas por adolescentes em trajetória infracional. 0 que, em tese, desmistificaria a ideia geral do expressivo envolvimento de adolescentes no cometimento de atos gravosos.

Agregando ao exposto, $\mathrm{Kahn}^{44}$ informa que, tomando como base pesquisa do ONU em 55 países, na média os jovens representam $11,6 \%$ do total de infratores, enquanto no Brasil a participação dos jovens na criminalidade está em torno de 10\%. Portanto conforme citado autor, os números estão “dentro dos padrões internacionais e abaixo mesmo do que se deveria esperar, em virtude de carências generalizadas dos jovens brasileiros" 45 .

Dessa forma percebe-se que o cometimento comparativo de atos gravosos e percentual de adolescentes envolvidos na criminalidade justificariam a tese da redução da imputabilidade penal.

\footnotetext{
44 Tabela retirada do www.tjmg.jus.br/ciabh e www.defesasocial.mg.gov.br/socioeducativo no dia $10 / 10 / 2011$.

45 Tabela retirada do www.tjmg.jus.br/ciabh e www.defesasocial.mg.gov.br/socioeducativo no dia $10 / 10 / 2011$
} 


\section{CONCLUSÃO}

Pelo exposto tem-se claramente que os principais argumentos aludidos por aqueles que são favoráveis à redução da imputabilidade penal não se sustentam. O Brasil possui idade penal idêntica à maioria dos países do mundo; crimes de alto potencial ofensivo são exceções dentro do arranjo criminal; taxa de adolescentes envolvidos em atos infracionais são menores se comparada e média global e a instrução processual caminha de forma mais dinâmica, o que eleva a sensação de efetividade à prestação jurisdicional.

Por outro lado é interessante imaginar de que forma a redução poderia contribuir na chamada "ressocialização" do adolescente autor de ato infracional. Como é de conhecimento de todos, o Brasil possui um sistema carcerário que, na grande maioria dos casos, não está preocupado da recuperação dos presos, mas sim em privá-lo do contato com a sociedade fora Unidade Prisional. Portanto, para quem seria essa solução de "atirar" num sistema tido como falido, superlotado, que pouco se preocupa com a recuperação efetiva do preso, milhares de adolescentes? É no mínimo ilusório pensar na redução da imputabilidade como solução. Na verdade poder-se-ia está dando mais um passo para a falência total do sistema carcerário brasileiro.

Dessa forma, pelo exposto no trabalho, não se pode pensar na redução da idade penal como medida indutora da redução da participação de adolescentes em atos infracionais. Há que se discutir, antes de qualquer coisa, a questão do envolvimento do adolescente enquanto fenômeno social, pensando na efetiva inclusão social dessa massa marginalizada da sociedade. Além disso, não se pode deixar de problematizar que muito se discute sobre a ineficácia do Estatuto da Criança e do Adolescente sem, contudo promover uma discussão sobre sua real aplicabilidade. Atualmente pouco do que o ECA se propôs a regular é aplicado. Não se têm conselhos tutelares efetivos ou mesmo existentes na maioria dos municípios, a medida de meio aberto um pouco aplicada e executada, os estabelecimentos socioeducativos não são adequados do ponto de vista arquitetônico, muito menos oferecem atendimento condizentes com o preceituado, etc. $O$ que leva a seguinte conclusão: $O$ que se critica na verdade não é o ECA e sua aplicabilidade, pois este é um instrumento que passados mais de 20 anos de sua elaboração ainda não foi efetivamente aplicada na sociedade brasileira. Ou seja, têm-se questões anteriores ao rebaixamento da imputabilidade penal que a sociedade brasileira deveria se preocupar. É o velho senso nacional de que tudo se resolverá com uma simples alteração normativa. 


\section{REFERÊNCIAS}

ALVES, Ariel de Castro. Brasil - Os Avanços e Desafios do ECA (Estatuto da Criança e do Adolescente). 20.08.08. Disponível em: http://www.adital.com.br/site. Acesso em: 28 de set. 2011.

ASSUMPÇÃO, André Del Grossi. Processo de Aplicação da Medida Socioeducativa. Disponívelem:http://www.datavenia.net/artigos/Direito_Processual_Penal/processoaplicacaom edidasocieducativa. Acesso em: 14 out. 2011.

BARBOSA. Flávia de Carvalho. Um olhar sobre o atendimento sócio-educativo nas medidas de internação em Minas Gerais. Dissertação apresentada à Escola de Governo Paulo Neves de Carvalho. Belo Horizonte. 2008.

BARROS, Wellington Pacheco. A interpretação sociológica do direito. Porto Alegre: Livraria do Advogado, 1995.

BETTIOL, Giuseppe. Direito Penal. Padova. Cedam, v. 2, 1973.

BITTENCOURT, Cezar Roberto. Tratado de Direito Penal: Parte Geral 1. São Paulo. Saraiva, 2006.

BRASIL. Constituição da República Federativa do Brasil. 27. ed. São Paulo: Saraiva, 2001. (Coleção Saraiva de Legislação).

BRASIL. Lei n. 8.069, de 13 jul. 1990. Dispõe sobre o Estatuto da Criança e do Adolescente e dá outras providências. Diário Oficial, Brasília, 16 jul. 1990.

CAVALLIERI, Alyrio. Falhas do Estatuto da Criança e do Adolescente. Rio de Janeiro: Forense, 1997.

Código Penal Português. Disponível em: http://www.portolegal.com/CPENAL.htm. Acesso em 20/10/2011.

COSTA JÚNIOR, Paulo José. Curso de direito penal - Parte geral. São Paulo: Saraiva, v. I 1992. FOUCAULT, Michel. Vigiar e punir: o nascimento da prisão. Tradução de Ligia M. Ponde - Vassal. Petrópolis: Vozes, 1977.

CUNEO, Mônica Rodrigues. Inimputabilidade não é Impunidade: Derrube este Mito, Diga não à Redução da Idade Penal, in Idade da Responsabilidade Penal. Belo Horizonte, 2003.

CURY, Munir. Reduzir a Idade Penal não é Solução. in Idade da Responsabilidade Penal. Belo Horizonte, 2003. 
FRAGOSO, Heleno Cláudio. Lições de direito penal - A nova parte geral. 4. ed. Rio de Janeiro. Forense, 1994.

HUNGRIA, Nélson. Comentários ao Código Penal. Rio de Janeiro: Forense, v. I, 1958.

LOBO, Silvana Lourenço. A Idade no Direito Penal Brasileiro da Menoridade. Belo Horizonte. Ed Madamentos, 2008.

JESUS, Damásio E. de. Direito penal. São Paulo: Saraiva, V. I, 2010.

KAHN, Túlio. "Redução da maioridade penal: Delinqüência juvenil se resolve aumentando oportunidades e não reduzindo idade penal". Disponível em:

www.nossacasa.net/recomeco/0069.htm. Acesso em: 20/10/2011.

MIRABETTE, Julio Fabbrini. Manual de Direito, volume I: parte geral, arts. 1 a 120 do Codigo Penal, 2010. São Paulo.

MORAES, Alexandre. Direito Constitucional. 12. ed. São Paulo: Atlas, 2002.

MÉNDEZ, Emilio García. Infância e Cidadania na América Latina. São Paulo: Hucitee/Instituto Ayrton Senna, 1998.

NETO, Félix Araújo. Teoria do Delito: Algumas Considerações sobre o Causalismo e Finalismo. Disponível em http://jus2.uol.com.br/doutrina/texto.asp?id=6245, no dia 11/09/2010.

NORONHA, E. Magalhães. Direito penal. Rio de Janeiro: Forense, V. III, T. I. 1978.

NUNES, Francisco Clávio Saraiva. Redução da Maioridade Penal: Uma Pseudo-Solução. in Idade da Responsabilidade Penal. Belo Horizonte, 2003.

PEREIRA, João Batista Costa. A Maioridade: Uma Visão Interdisciplinar. Jus Navigandi, Teresina, ano 7, n. 60, nov. 2002. Disponível em: <http://jus2.uol.com.br/doutrina/texto.asp?id=3491>. Acesso em: 12 out. 2010.

QUEIROZ, Bruno Caldeira Marinho de. Evolução Histórico Normativa da Proteção e Responsabilização Penal Juvenil no Brasil. Disponível em:

http://artigos.netsaber.com.br/resumo_artigo_6912/artigo_sobre_evolucao_historiconormativa_da_protecao_e_responsabilizacao_penal_juvenil_no_brasil. Acesso em: 12/10/2011.

SARAIVA, João Batista Costa. Adolescente em Conflito com a Lei - da indiferença à proteção integral: uma abordagem sobre a responsabilidade penal juvenil. 1 ed. Porto Alegre: Livraria do Advogado, 2003.

SARAIVA, João Batista Costa. A Idade e as Razões: Não ao Rebaixamento da Imputabilidade Penal, in Idade da Responsabilidade Penal. Belo Horizonte, 2003.

SIMONETTI, Joelma. Menoridade Penal: existe impunibilidade ? Disponível em: http: / /www.ambito-

juridico.com.br/site/index.php?n_link=revista_artigos_leitura\&tartigo_id=2412. Acesso em 30 de out. 2011. 
ISSN 1981-3694

(DOI): 10.5902/1981369413692

REVISTA ELETRÔNICA DO CURSD DE

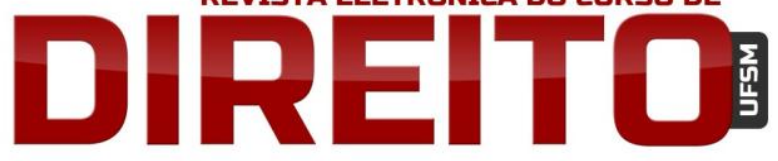

REDUÇÃO DA MAIORIDADE PENAL: DISCUSSÃO ACERCA DESSA

PROPAGADA SOLUÇÃO PARA REDUÇÃO DA CRIMINALIDADE JUVENIL

TOLEDO, Francisco de Assis. Princípios básicos de direito penal. São Paulo: Saraiva, 1991.

Recebido em: 01.05.2014

Revisões em: 04.06.2014

Aprovado em: 03.07.2014 